\title{
Topics in Question: Active Learning through Inquiry
}

\section{Susan Lundvall Brodie}

University of Wisconsin/Washington County

"Children enter schools as question marks and leave as periods." (Postman and Weingartner 1969)

"It is a tragic fact that most of us only know how to be taught; we haven't yet learned how to learn. [Given that the half-life of facts may be ten years or less these days], the real aim of education should be to develop skills of inquiry." (Knowles 1975)

$\mathrm{T}_{\mathrm{h}}$ hese two statements arrest my attention, but it is the landscape between them that I want to explore. Why are so many students poor questioners why do they lack habits and skills in so fundamental a human activity as inquiry? And why, if it is true that the best teaching capitalizes on students' natural curiosity, do so many students appear to lack the very gift we wish to tap?

Let me begin my investigation with a scenario. A typical assignment in my English composition course is what I call an "issue paper," which asks students to research and evaluate some issue that is personally important to them. I advise the students to begin their exploration with a question or series of questions about the issue, and to write the question(s) at the top of a sheet before researching - the question to serve as both a guide and as a reminder of the need to keep an objective view as they investigate. But when research time rolls around, what do I too often get? "Topic: Acid Rain" or "Topic as question: The causes of acid rain."

From To Improve the Academy: Resources for Student, Faculty, and Institutional Development, Vol. 7. Edited by J. Kurfiss, L. Hilsen, S. Kahn, M.D. Sorcinelli, and R. Tiberius. POD/New Forums Press, 1988. 
Even when this topic is, in fact, stated as a question ("What are the causes of acid rain?"), I know the student is not likely to get very far: the "question" as posed leads too readily to fixed answers and hence to quick closure. What is the problem here? Is the task I have set too difficult? Is it the "topic" alone that fails to engage the student in a meaningful pursuit? Or does the problem lie in students' tendencies (far too prevalent) to seek ready-made "book answers," to parrot researched information and, hence, to limit themselves to mechanical exercises in shuffling research without analyzing, synthesizing or evaluating it? The problem lies in all three areas, I think - and more.

In my experience, a majority of freshman students do tend to grasp for readymade topics, topics that leave little room for personal engagement. These topics, then, remain just that mere topics - until students recognize ways in which they represent real, personally compelling issues. Is this requirement active engagement too "hard"? Perhaps, especially if it is foreign to the students' experience and understanding of what is expected in meaningful writing and research. The result? Often, instead of analytical papers, students generate reports, book searches, "xerox and shuffle" affairs done with no real sense of inquiry, and little, if any, true analysis or interpretation. Even in persuasive writing, students tend to rush after a fixed point of view, and to conceive of "research" as an effort to locate articles that will support that view. This apparent discomfort with "looking into" matters seems to me to represent a major impediment to learning. The students' activity is mechanical; there is no sense of pursuit, of investigation, of inquiry, of discovery and of capture.

Why is it so difficult for students (or anyone, for that matter)to ask questions, and, hence, truly to engage in acts of inquiry and fruitful investigation? Richard A. Wertime (1986, p. 2) gets to the heart of the problem when he tells us that, for many people, asking a question is tantamount to admitting a deficiency. It is, he reasons, an act of "self-demotion." Many people cannot or will not readily tolerate such self exposure; it is simply too painful. Many people lack the self-confidence necessary to take the risk of exposing their deficiencies. And, obviously, it takes a certain degree of knowledge before we even know whether or not the questions we risk asking are, in fact, "good questions." Wertime echoes a variety of researchers who suggest that asking questions is indeed difficult, and often tenaciously avoided, because it involves a fear of being judged. This fear, it seems, represents the primary psychological constraint for teachers who wish to develop skills in questioning and inquiry. And, as I will show later, it is precisely this natural fear that many traditional classroom questioning methods tend to intensify. 
There are other constraints that loom just as large. Some of the toughest to address are developmental in nature. Many students come to us at that stage of cognitive and emotional growth characterized by clinging to rules, to polarized views of right and wrong. It is not surprising, then, that students at these stages of development typically clutch after what Wertime calls "the safety of received ideas" (p. 2). To complicate matters, studies by Lawton (1963) show that family patterns and cultural factors can also affect one's personal scheme, and thus one's attitudes towards questioning. When students have not experienced much open discussion or debate as a part of family life, they are not typically reflective or intensely interested in ideas. Tangential to these conceptual and cultural constraints are the feelings of taboo often associated with questioning conventional ideas, "accepted facts," or (worse) one's own beliefs - open and existential questions that involve risks above and beyond cultural pressures.

In addition to psychological, developmental, and socio-cultural constraints - the ones we feel least able to address or control - are the constraints we can, perhaps, do something about. These are pedagogical in nature. The quote from Postman and Weingartner at the head of this article asks us to pause and consider what our students have been conditioned to expect, and how their primary and secondary educational experiences correlate with college faculty expectations. Most researchers tend to concur that the typical high school graduate has become "rule bound"; emphasis on rote learning and lecture formats(despite their obvious value) has tended to promote passiveness and closure - to dull curiosity and drive. In fact, a variety of studies examined suggest that the bulk of questioning done at grade and high school levels aims primarily at "checking" for recall of detail; the chief purpose is not so much to promote thinking, as to test for memory and "correctness." Don Nix of IBM's Watson Research Center concludes that "such questioning may teach the student that comprehension consists of mere recall of specific facts from a text.... This response type can not be expected to lead to effective inferential comprehension" (1985, p. 298). Indeed, teacher-generated questioning of the sort Nix refers to can block discovery and inhibit cognitive growth.

The situation is complicated, as Bean (1985) suggests, because while many teachers believe that they encourage inquiry and divergent thinking, they are, in fact, after answers and not exploration. As a result, what passes as "discussion" too often turns out to be little more than a "calling on" procedure. Bean concludes that even though teachers expect and tend to reward divergent thinking, their actual methods too often encourage quite the opposite: early closure. 
Finally, David Bartholomae (1983) contends that many students come to us with little skill in inquiry or exploration because our educational system has become product bound. The heavy emphasis on the sissupport essays, for example, leads students to close a subject down, rather than open it up to explore its possibilities. This pattern is precisely what concerns me, for it narrows our students' conception of what education is all about. As Zeiger concludes, "we are implicitly teaching that the ability to support an assertion is more important than the ability to examine an issue. In doing so, we fail in our duties as liberal educators" (1985, p. 458).

Confronted with such a tangle of problems and constraints, what can be done? Two solutions come immediately to mind. The first is to understand that part of our duties as liberal educators is to create an atmosphere in which students can take risks, learn to pose questions, and discover some measure of personal and cultural relevance in the knowledge they are asked to master. The second (and perhaps easier) solution is for teachers to give direct instruction in strategies of inquiry, and to make those strategies explicit in all reading, discussion, and writing assignments. In addition, it is important to include questioning patterns that attend to differences in students' developmental levels (i.e., concrete operational or dualistic thinkers). Too often, students perceive of our objectives and strategies as part of a "hidden agenda"; we should take time to clearly and fully explain what our methods of inquiry will be, what our expectations are, and why. In the end, our ability to recapture students' curiosity and engagement depends, to a considerable degree, on our ability to empower students with the thinking skills and strategies that drive learning in our particular domains. We confront three interrelated tasks: improving motivation and engagement, teaching inquiry skills, and addressing students' different developmental levels.

Let me return now to my initial scenario. What line of questioning, and what kinds of informal, nonthreatening prewriting exercises might help to more meaningfully engage the student who has dead-ended with the topic of acid rain? Initially, I can think of no more useful strategy than journalism's 5Ws: who, what, when, where, why/how are the questions I ask my composition students to look for in their reading, and to pursue in their writing. I can think of no discipline or academic task that would not in some way lend itself to preliminary investigation based on this strategy (with the possible exception of mathematics). The strategy is simple, widely used, and not easily forgotten. And, since the first four questions are fact-based and concrete in nature, they provide students at any developmental level with a basis from which to begin moving into complex issues. Moreover, I like to use the journalists' line of inquiry to introduce students to the kind of real-life, active pursuit that makes news and editorial writ- 
ing seem so much more purposeful and active than much of academic writing tends to be. In fact, when students begin to investigate personal and local ramifications of an issue, and when they conceive of writing as a pursuit of questions that are both personally and socially relevant (guided by the curiosity of their teachers and peers), they can, for example, begin to work their way into longer papers by writing editorials for school or local newspapers. This intermediate assignment gives students a livelier sense of purpose and audience than they might initially have in response to a research assignment, and the prospect of actually appearing in print (as several of my students have) adds immeasurably to motivation.

Briefly summed, then, the bulk of my students' assignments take them through the following series of activities, all driven by the 5Ws: gathering information, interviewing appropriate people for added professional insight or public opinion, journal writing and group discussion to develop a sense of angle and lead, and then writing documented editorials. This emphasis on "real" investigation and "real" writing tends to move students toward the research paper with a greater sense of involvement and purpose, and with a more genuine sense of voice than the typical rigid and formulaic conception of academic writing permits. Let's see how this system might work. In her journal, the student with the topic of acid rain is coached to ask and respond: what is acid rain? where is it prevalent? when did it become a problem? who is affected? how is it produced and how can it be controlled? After this preliminary and private journal writing, she can begin to pursue questions of personal or local relevance during small-group coaching sessions aimed at discovering what others might find interesting in the student's topic. Hence, curiosity is created in the group setting, at the same time the student gains increased perspective from peer questions. Group discussion also helps to move students from their initially limited views of factual information toward more purposeful and meaningful lines of inquiry.

Returning to her journal, our student's thinking begins opening to more fruitful possibilities (still using the $5 \mathrm{~W}$ strategy): how is the ordinary citizen affected by acid rain (I know how farmers and fishermen are affected, but how am I personally affected)? Where in my immediate environment is acid rain a threat? Who is trying to control this kind of pollution? How successful have clean-up attempts been? We can see now how these preliminary questions help students move into questions of personal relevance, but at the same time, they begin to tackle more openended questions involving higher order thinking skills(i.e. the "how," the "why," and the "what if" of an issue). Thus, the student's pursuit might continue to move something like this: will my health be jeopardized, or the health of prospective children? If I plan a career in agriculture, home 
economics, health care, or tourism, how will my future be affected? If I plan a career in business, might I need to respond to legislation aimed at reducing acid rain pollution? Does the ordinary citizen really know the facts on the nature of the hazards posed by acid rain in our country/state/area? Students who are encouraged to ask questions of personal relevance are much better able to engage in the learning process; they more readily find real topics to pursue; and they find their investigations more compelling and rewarding than students who grope their way around global issues or confine themselves to standard arguments often based on isolated studies or limited examples.

Moreover, this simple 5W strategy not only invites questions leading to personal engagement, it also incorporates a progression of higher order thinking tasks similar to those outlined by Benjamin Bloom in the mid50's. Bloom's taxonomy dovetails nicely with theories of cognitive development described by Perry and Piaget. Bloom's taxonomy suggests a hierarchy of questions ranging in complexity from concrete questions of knowledge and understanding, through more complex operations involving application, analysis, synthesis, and finally evaluation (Bloom, Engelhart, Frost, Hill, \& Krathwohl, 1956). Students at a concrete operational level of cognition can best respond to tasks involving questions of recall and comprehension; tasks involving application are more approachable when information has been mastered at the comprehension level. In other words, it is fruitless to ask students to leap at once into analysis or evaluation (the how,why, and what if). We must help them build up to complex assignments by structuring preliminary exercises and discussions around more concrete questions.

Consistent use of strategies such as the $5 \mathrm{Ws}$ can help students form efficient habits of mind that will enable them to progress from basic/concrete to abstract/higher order cognitive operations. For example, "who, what, when, where" are questions of knowledge and comprehension that must precede more complex questions of application (if acid rain spreads pollutants via wind currents, how can I detect acid rain pollution in my immediate environment, and what can I do to reduce this pollution, etc). At the same time, though, factual material needs to be explored through questions of personal relevance; and private questioning must eventually "go public" (through group discussion and interviewing) before most students can credibly support a stand on an issue (analysis/synthesis), propose a solution (application), or begin an evaluation of proposed legislation or an assessment of public awareness.

Finally, no learning strategy can be truly beneficial unless students have constant practice in non-threatening situations. For over 25 years, researchers in the fields of rhetoric and composition theory have advo- 
cated the use of journals to provide such practice, encouraging private and personal writing to promote cognitive growth. Most notably, Emig (1977), Baker (1983), and Fulwiler (1983) have shown that journals offer students the privacy to err, and promote what I'm sure we all want more of: the willingness to play with ideas and to risk the questions that often lead from ignorance to breakthrough thinking. By assigning a substantial number of points (but no letter grade) to journals, and by giving them a central role in routine class procedures, teachers can encourage students to discover what powerful learning tools writing and questioning really are. Moreover, consistent use of journals gives students the experience with prewriting and even with "failure" that are a necessary bridge to higher order cognition. Such a method gives students an optimal chance to discover the lines of inquiry they can honestly engage in and can reasonably succeed in handling.

I am greatly indebted to my colleague, Lesley Ann Rex, of the University of California-Santa Barbara, for the idea of using question-based journals to spur both individual and class discussion. Her experience with what she calls the "Question Journal," like mine using a similar approach, has shown that when teacher and students regularly share their questions, curiosity about other people's questions and pursuits becomes quite infectious. As students begin to concentrate less on "answers," a potentially high-anxiety atmosphere can be transformed into one that encourages the individual voice with its unique and urgent questions. Moreover, students soon discover that the best questions are not fully answerable, and in this way they begin stretching toward an understanding that truth is many-faceted and solutions to our pressing issues come in differing, often conflicting, possibilities. It is the habit of actively questioning and pursuing these possibilities that opens the intellect and empowers students; only by fostering inquiry can we promote the kind of life-long learning skills that liberal educators see as their highest goal.

\section{References}

Baker, S. (1983). Writing as learning. In P. L. Stock (Ed.), Fforum: Essays on theory and practice in the teaching of writing (pp. 24-32). Upper Montclair, New Jersey: Boyton/Cook.

Bartholomae, D. (1983). Writing assignments: Where writing begins. In P. L. Stock (Ed.), Fforum: Essays on theory and practice in the teaching of writing (pp. 300-3112). Upper Montclair, New Jersey: Boyton/Cook. 
Bean, T. (1985). Classroom questioning strategies: Directions for applied research. In A. C. Graesser and J. B. Black (Eds.), The psychology of questions (pp. 335-358). Hillsdale, New Jersey: Erlbaum.

Bloom, B. S., Engelhart, M.D., Frost, E. J., Hill, W. H. \& Krathwohl, D. R. (1956). Taxonomy of educational objectives. Handbook I: Cognitive domain. New York: David McKay.

Emig, J. (1977, May). Writing as a mode of learning. College Composition and Communication, pp. 122-128.

Friere, P. (1975). Pedagogy of the oppressed. New York: Harder \& Harder.

Fulwiler, T. (1983). Why we teach writing in the first place. In P. L. Stock (Ed.), Fforum: Essays on theory and practice in the teaching of writing (pp. 273-286). Upper Montclair, New Jersey: Boyton/Cook.

Knowles, M. (1975). Self-directed learning. New York: Follett.

Lawton, D. (1963). Social class differences in language development: a study of some samples of written work. Language and Speech, 6, pp. 120-143.

Nix, D. (1985). Notes on the efficacy of questioning. In A. C. Graesser \& J. B. Black (Eds.), The psychology of questions (pp. 297-333). Hillsdale, New Jersey: Erlbaum.

Olson, D. R. (1977). The languages of instruction: The literate bias of schooling. In R. C. Anderson, R. J. Sprio \& W. E. Montague (Eds.), Schooling and the acquisition of knowledge (pp. 65-89). Hillsdale, New Jersey: Erlbaum.

Postman, N. \& Weingartner, C. (1969). Teaching as a subversive activity. New York: Delacorte.

Wertime, R. A. (1986, May/June). The act of questioning. Teaching Thinking \& Problem Solving 8(3), pp. 16.

Zeiger, W. (1985, September). The exploratory essay: Enfranchising the spirit of inquiry in college composition. College English 47, pp. 454465. 